\title{
The Effect of Physical Exercise as A nursing Intervention on Management of Positive and Negative Symptoms of Schizophrenic Patients
}

\author{
Ola Ali Abd El-Fatah, Hoda Diab Fahamy Ibrahim, Alaa Eldin Mohamed Darweesh, Nadia Ibraheem Sayied \\ \& Reda Abd Elaal Thabt.
}

Assistant lecturer of Psychiatric -Mental Health Nursing, Faculty of Nursing, Assiut University Egypt. Professor of Community Health nursing, Faculty of Nursing, Assiut University Egypt.

Professor of Psychiatry, Faculty of Medicine, Assiut University Egypt.

Assistant Professor of Psychiatric Mental Health Nursing, Faculty of Nursing, Assiut University Egypt. lecturer, of Psychiatric Mental Health Nursing, Faculty of Nursing, Assiut University Egypt.

\begin{abstract}
The health benefits of physical activity and exercise are well documented and these effects could help people with schizophrenia. This study aimed at implementing and evaluating physical exercise program as nursing intervention on management of positive and negative symptoms of schizophrenic patients. Subjects and methods: The study was carried out at the psychiatric inpatient unit of the department of Psychiatry and Neurology at Assiut University Hospital and Assiut mental health hospital. The study included one hundred patients with schizophrenic disorder. They were classified into two subgroups. One of them as experimental group ( $\mathrm{No}=50)$ assigned to 45 minutes of physical activities and the other as a control group $(\mathrm{No}=50)$. Each patient was evaluated through Socio Economic Assessment scale, Positive and Negative Syndrome Scale, Nurse's Observation Rating Scale, and the Arabic version of self image questionnaire. Results showed that there were statistically significant difference in total PANSS, NORS, and self concepts scores of experimental than control group. The study concluded that symptoms of schizophrenia respond better in patients received physical exercises and usual treatment than in control group who receive usual treatment only. Recommendation: Addition of physical activity program to the management plan of schizophrenics to improve out come of their treatment.
\end{abstract}

\section{Key Words: Schizophrenia, Physical Activity \& Psychiatric Patients}

\section{Introduction}

Advanced research proved that physical activity has a beneficial effect upon people's physical and mental health. Physical activity has been reported to help in a wide spectrum of issues ranging from self-esteem and sense of social inclusion to patients with psychiatric disorders such as schizophrenia, depression, and anxiety. Overall, there seem to be four avenues for these effects: prevention of poor mental health; improvement in mental health; treatment of mental disorders; and improvement in the quality of life of persons with mental illnesses, also improvement of physical health (Green et al., 2000).

Physical exercise is important for maintaining physical fitness and can contribute positively to maintaining a healthy weight, building and maintaining healthy bone density, muscle strength, and joint mobility, promoting physiological wellbeing, and strengthening the immune system. Exercise also reduces levels of cortisol. Cortisol is a stress hormone that builds fat in the abdominal region, making weight loss difficult. Cortisol causes many health problems, both physical and psychological (Cohen \&Williamson., 1991).
Physical activity defined as any bodily movement produced by skeletal muscles that require energy expenditure. Alternatively, any musculoskeletal activity increases the organism's energy expenditure above its resting rate (WHO, 2011). Exercises are divided into three types depending on the overall effect they have on the human body: Flexibility exercises, includes stretching, improve the range of motion of muscles and joints (O'Connor et al., 2005). Aerobic exercises includes cycling, swimming, walking, skipping rope, rowing, running, hiking or playing tennis (Wilmore \& Knuttgen, 2003). Anaerobic exercises, such as weight training, functional training, eccentric training or sprinting, increase short-term muscle strength (Devos et al., 2005).

Aerobic exercise seems to be effective in improving general mood and symptoms of depression and anxiety in healthy individuals and psychiatric patients. This effect is not limited to aerobic forms of exercise. There are almost no contraindications for psychiatric patients to participate in exercise programs, provided that they are free from 
cardiovascular and acute infectious diseases (Meyer \& Broocks, 2000).

According to World Health Organization (2011) schizophrenia is a severe form of mental illness affecting about 7 per thousand of the adult population, mostly in the age group 15-35 years. the prevalence is high due to chronicity. Schizophrenia affects about 24 million people world wide. Schizophrenia is treatable disorder, treatment being more effective in its initial stages. More than $50 \%$ of persons with schizophrenia are not receiving appropriate care and $90 \%$ of people with untreated schizophrenia are in developing countries.

Gorczynski \& Faulkner ( 2011) found that regular exercise and physical activity is thought to improve both physical and mental health. Regular exercise can help individuals with schizophrenia to improve their physical and mental health and well-being.

The majority of research studies reviewed by Stathopoulou et al., (2006) state that it is important to mention that for safety reasons, the necessity of a professional physical assessment before enrolment in any physical activity program. Sudden physical exercise in people who are unfit can cause physical injury to muscles and joints, disturbed diabetes, affect the heart and respiratory system.

\section{Significance of the study}

There is a growing recognition that physical activity can enhance mental health with regard to the effects of exercise on schizophrenia, exercise is associated with an alleviation of negative symptoms associated with schizophrenia, such as depression, low selfesteem and social withdrawal (Faulkner, 2005).

Aerobic exercise could be effective in improving general mood and symptoms of depression and anxiety in healthy individuals and psychiatric patients. This effect is not limited to aerobic forms of exercise. There are almost no contraindications for psychiatric patients to participate in exercise programs, provided that they are free from cardiovascular and acute infectious diseases (Meyer \& Broocks, 2000).

Nurses are particularly appropriate for this role due to the close bonds and trust developed with consumers which provides unique insight into individual circumstances (Happell et al., 2011). For instance, in mental health care settings, nurses have first-hand awareness of the physical health barriers faced by individual consumers, a sense of their progress with mental illness management and recovery, and their level of support from friends, family and caregivers (Hardy \& Gray, 2010).

Thus we need to create physical activity as nursing intervention to developed advanced nursing care for patients with schizophrenic disorders, to promote the mental wellbeing of schizophrenic patients, either those with active psychiatric symptoms and those in remission.

\section{Aim of the study}

To implementing and evaluating physical exercise program as nursing intervention on management of positive and negative symptoms of schizophrenic patients.

\section{Subjects and methods}

\section{Research Design}

A Quasi experimental research design was used in the study.

\section{Setting}

The study was carried out at the psychiatric inpatient unit of the department of Psychiatry and Neurology at Assiut University Hospital and Assiut mental health hospital.

\section{Subjects}

Sample of the study were convenient included one hundred patients with schizophrenic disorders diagnosed according to DSM-IV-TR. They were classified into two subgroups. Group (I) included fifty patients who received usual treatment in the form of 2nd generation antipsychotics with or without electro compulsive therapy in addition to physical activity as nursing intervention as experimental group. Group (II) included fifty patient who received usual treatment in the form of 2 nd generation antipsychotics with or without electro convulsive therapy as the control group.

\section{Tools of the study}

Five tools for collecting data:

\section{Tool I consists of socio demographic data Socio demographic data sheet}

It includes interview sheet developed by the researcher, and designed to include socio demographic data about the patients such as name, age, gender, level of education, occupation, marital status, date of admission, residence...etc

\section{Tool II Standard psychiatric interview}

This tool is completed by researcher after confirming diagnosis by psychiatrist.

$\mathrm{t}$ through standard psychiatric interview for diagnosis: Each patient would subjected to the following:

a. Psychiatric interview for clinical assessment to confirm diagnosis according to DSM-IV-TR (APA, 2000).

b. Medical history and complete physical examination by internal medicine specialist 
(diagnosis, onset of illness, family history......etc, ).

c. Investigation as ECG, kidney function testes, or chest $\mathrm{x}$-ray to verify their fitness for physical effort.

Psychometric scales

\section{a. Tool III}

It includes Positive and Negative Syndrome Scale (PANSS) (Kay et al., 1987). The PANSS is a rating scale used to assess the positive symptoms, negative symptoms, and general psychopathology specifically associated with schizophrenia. The scale consists of 30 items. Each item is rated on a scale from 1 (symptom not present) to 7 symptoms extremely severe.

\section{b. Tool IV}

It includes the Arabic version of Offer, Ostrave and Haward's self image questionnaire (1982) which translated by Abo El Maged (2001). This scale was utilized as a mean to assess self-concept. This questionnaire consists of eleven subscales which cover the five components of self-concept as follows:- the psychological self, the social self, the sexual self, the family self, and the coping self.

\section{c. Tool V}

It includes Nurse's Observation Rating Scale (NORS) for inpatient evaluation. This scale, developed by Honigfeld et al., (1966) and translated into Arabic version by Sayied (2008), was used to assess changes in daily life activities and psychosocial functioning of the patients during hospitalization and during follow- up period. This scale includes 22 items divided into 8 items (personal appearance, mannerisms \& posturing, thought \& talk, mood \& affect, motor activity, irritability, social competence \& social performance, and delusion). The 4 categories of scale were coded on a five-points scale

$(1=$ never, 2 = occasionally, $3=$ often, $4=$ frequently, $5=$ almost always). Formulas are used to compute a total score and four factor scores. Score of this scale ranged from the upper score 110 and the lower score 22.

The program of physical exercises as nursing intervention:

The designed program included the following: the patients divided into small groups (maximum 5 patients) for each group which perceives program included 12 sessions per month 30-45 minutes duration offered 3 times per week to each group. Data were collected from the first of September 2012 to the end of August 2013.

Each session of the nursing intervention of physical activity consisted of six parts and conducted by the researcher. The sessions begin with:

Part (1) : Relaxed deep breathing for 5 minutes.
Part (2) : Muscle flexibility exercises 5-10 mints slow stretch of major muscle groups.

Part (3) : Warm-up exercises for 5 minutes.

Part (4) : Endurance training 5-10 minutes (cycle ergometry).

Part (5) : Muscle strengthening 5-10 minutes (abdominal muscles and large muscles of arms and legs)

Part (6) : Relaxed deep breathing for 5 minutes.

Methods of teaching used in the program:

Methods of teaching have been used in each group session includes demonstration, lecture, \& role play.

\section{Media used in the program}

Media have been used in each group session includes video, hand out, \& Posters.

Process of development physical exercises as the nursing intervention

The following phases were carried out to develop the Physical activity as nursing intervention:

First: Assessment phase

This phase done by researcher and psychiatrist was aimed to assess physical fitness for patient activity as well as assessment of patient levels of self concept. Patients selected for the study program were subjected to physical examination and investigation as ECG, kidney function testes, and chest x-ray, to verify their fitness for physical effort. Physical fitness assessments were made to all patients before their participation in the physical activity by physician and researcher. The body weight and waist girth were recorded. Any abnormalities of posture and gait were noted, and inquiry about previous or ongoing orthopedic, neurological, cardiovascular, or respiratory problems. Muscles flexibility evaluated by assessment of full body range of motion thorough joint, neck, four limbs movements, and the flexibility of the trunk muscles during walking.

\section{Second: Planning phase}

Physical activities program consisted of 12 sessions per month include one session every other day (three times per week) and lasts for four weeks. Each session lasted for 30-45 minutes and consists of 6 parts. Part one began with a few minutes of relaxed breathing, performed in sitting positions. Patients were instructed to take diaphragmatic breathing. Part two warm-up exercises. In part three gentle muscle flexibility exercises were performed, followed by endurance training as part four. Part five muscle strengthening exercises were adapted to accommodate the individual needs of each patient and part six relaxed breathing exercise. Researcher use qualified athletic trainer to assist in the practical sessions for male patients and researcher do for female. 
Third: - Schedule of the program

The schedule of the program of Physical activity as nursing intervention strategy includes (time and number of sessions, teaching method). The teaching place and the facilities were checked for appropriateness. Number of sessions was 12 sessions, three sessions per week for 30-45 minute. The program conducted at the recreational hall in the hospital. Physical activity as nursing intervention implemented during four weeks in small group (maximum 5 patients) for 30-45 minutes duration offered 3 times per week. Each session of the nursing intervention of physical activity consisted of six parts and was conducted by the researcher.

Fourth: - Evaluation phases

Evaluation phases of the impact of physical activity as nursing intervention used two time one before the program and second time immediate post program.

\section{Ethical considerations}

An oral consent was obtained from all patients before collecting data. Explain to each patients aim of study. No harmful maneuver and no hazards were anticipated. Confidentiality was maintained during all steps of the study.

\section{Pilot study}

The pilot study was conducted on 10 patients with schizophrenic disorders, who were admitted to psychiatric inpatient unit. To tested the tool clarity and the time needed for filling the tool. This number excluded from total sample.

Method

An official permission was obtained from the Dean of the faculty of nursing-Assiut University directed to the dean of faculty of medicine to accept to start of the research at psychiatric unit of neurology and psychiatry department in Assiut university hospital. Another letter was directed to Ministry of health and population to accept starting in Assiut mental health hospital it's the policy in the hospital.

Statistical method

The data were tabulated and statistical analysis was performed with statistical package for social science (SPSS) version 18. Comparison between studied groups was performed with frequency, independent $\&$ paired T test and ANOVA test. The significance of difference calculates as 0.5 .

\section{Results}

Table (1) : Sociodemographic characteristics and assessment of the studied schizophrenic patients $(\mathrm{N} 0=50)$.

\begin{tabular}{|c|c|c|c|c|c|c|c|c|c|c|c|c|}
\hline \multirow{3}{*}{ Variables } & \multicolumn{6}{|c|}{ Experimental group (No. 50 ) } & \multicolumn{6}{|c|}{ Control group (No. 50 ) } \\
\hline & \multicolumn{2}{|c|}{ Total } & \multicolumn{2}{|c|}{ Males } & \multicolumn{2}{|c|}{ Females } & \multicolumn{2}{|c|}{ Total } & \multicolumn{2}{|c|}{ Males } & \multicolumn{2}{|c|}{ Females } \\
\hline & No. & $\%$ & No. & $\%$ & No. & $\%$ & No. & $\%$ & No. & $\%$ & No. & $\%$ \\
\hline Age & & & & & & & & & & & & \\
\hline $\begin{array}{l}<20 \text { years } \\
20-40 \text { years }\end{array}$ & $\begin{array}{c}3 \\
35\end{array}$ & 6 & 1 & 2.7 & $\begin{array}{l}2 \\
7\end{array}$ & $\begin{array}{l}15.4 \\
53.8\end{array}$ & $\begin{array}{c}2 \\
40\end{array}$ & $\begin{array}{c}4 \\
80\end{array}$ & $\begin{array}{c}2 \\
29\end{array}$ & $\begin{array}{c}5.3 \\
76.3\end{array}$ & $\begin{array}{c}0 \\
11\end{array}$ & $\begin{array}{c}0 \\
91.7\end{array}$ \\
\hline $40-60$ year & $\begin{array}{l}35 \\
12\end{array}$ & 24 & $\begin{array}{c}28 \\
8\end{array}$ & $\begin{array}{l}15.1 \\
21.6\end{array}$ & 4 & $\begin{array}{l}3.8 \\
30.8\end{array}$ & $\begin{array}{l}40 \\
8\end{array}$ & $\begin{array}{l}80 \\
16\end{array}$ & $\begin{array}{c}29 \\
7\end{array}$ & $\begin{array}{l}10.3 \\
18.4\end{array}$ & 1 & 8.3 \\
\hline $\begin{array}{l}\text { Mean } \pm \text { SD of } \\
\text { age }\end{array}$ & \multicolumn{2}{|c|}{$\begin{array}{c}33.4 \pm \\
11.6\end{array}$} & \multicolumn{2}{|c|}{$\begin{array}{c}33.19 \pm \\
11.54\end{array}$} & \multicolumn{2}{|c|}{$\begin{array}{c}34.15 \pm \\
12.23\end{array}$} & \multicolumn{2}{|c|}{$\begin{array}{l}30.96 \pm \\
10.04\end{array}$} & \multicolumn{2}{|c|}{$\begin{array}{l}30.66 \pm \\
9.92\end{array}$} & \multicolumn{2}{|c|}{$\begin{array}{c}31.92 \pm \\
10.79\end{array}$} \\
\hline $\begin{array}{l}\text { Martial } \\
\text { statues }\end{array}$ & 30 & 60 & 22 & 59.5 & 8 & 61.5 & 35 & 70 & 28 & 73.7 & 7 & 58.4 \\
\hline Single & 17 & 34 & 14 & 37.8 & 3 & 23.1 & 11 & 22 & 10 & 26.3 & 1 & 8.3 \\
\hline Married & 3 & 6 & 1 & 2.7 & 2 & 15.4 & 3 & 6 & 0 & 0 & 3 & 25 \\
\hline $\begin{array}{l}\text { Divorce } \\
\text { Widow }\end{array}$ & 0 & 0 & 0 & 0 & 0 & 0 & 1 & 2 & 0 & 0 & 1 & 8.3 \\
\hline \multicolumn{13}{|l|}{ Occupation } \\
\hline Not working & 24 & 48 & 12 & 32.4 & 12 & 92.3 & 22 & 44 & 12 & 31.6 & 10 & 83.4 \\
\hline Workers & 22 & 44 & 21 & 56.8 & 1 & 7.7 & 25 & 50 & 24 & 63.2 & 1 & 8.3 \\
\hline Employee & 4 & 8 & 4 & 10.8 & 0 & 0 & 3 & 6 & 2 & 5.2 & 1 & 8.3 \\
\hline \multicolumn{13}{|l|}{$\begin{array}{l}\text { Level of } \\
\text { education }\end{array}$} \\
\hline Illiterate & 17 & 34 & 10 & 27.0 & 7 & 53.8 & 15 & 30 & 10 & 26.2 & 5 & 41.7 \\
\hline Student & 1 & 2 & 0 & 0 & 1 & 7.7 & 2 & 62 & 2 & 5.3 & 0 & 0 \\
\hline $\begin{array}{l}\text { Secondary } \\
\text { school }\end{array}$ & 30 & 60 & 25 & 67.6 & 5 & 38.5 & 31 & 4 & 24 & 63.2 & 7 & 58.3 \\
\hline University & 2 & 4 & 2 & 5.4 & 0 & 0 & 2 & 4 & 2 & 5.3 & 0 & 0 \\
\hline
\end{tabular}

Vol , (3) No , (5) June 2015 


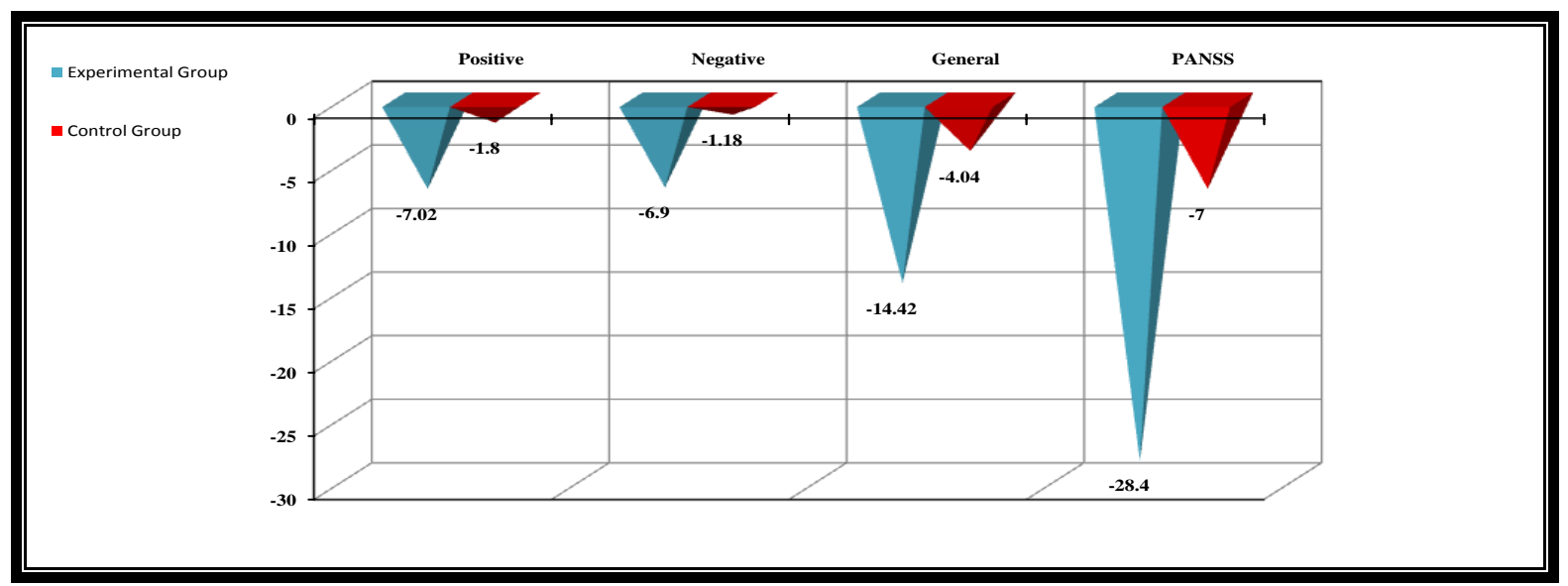

Figure (1) : Mean change of scores at different subscale of PANSS.

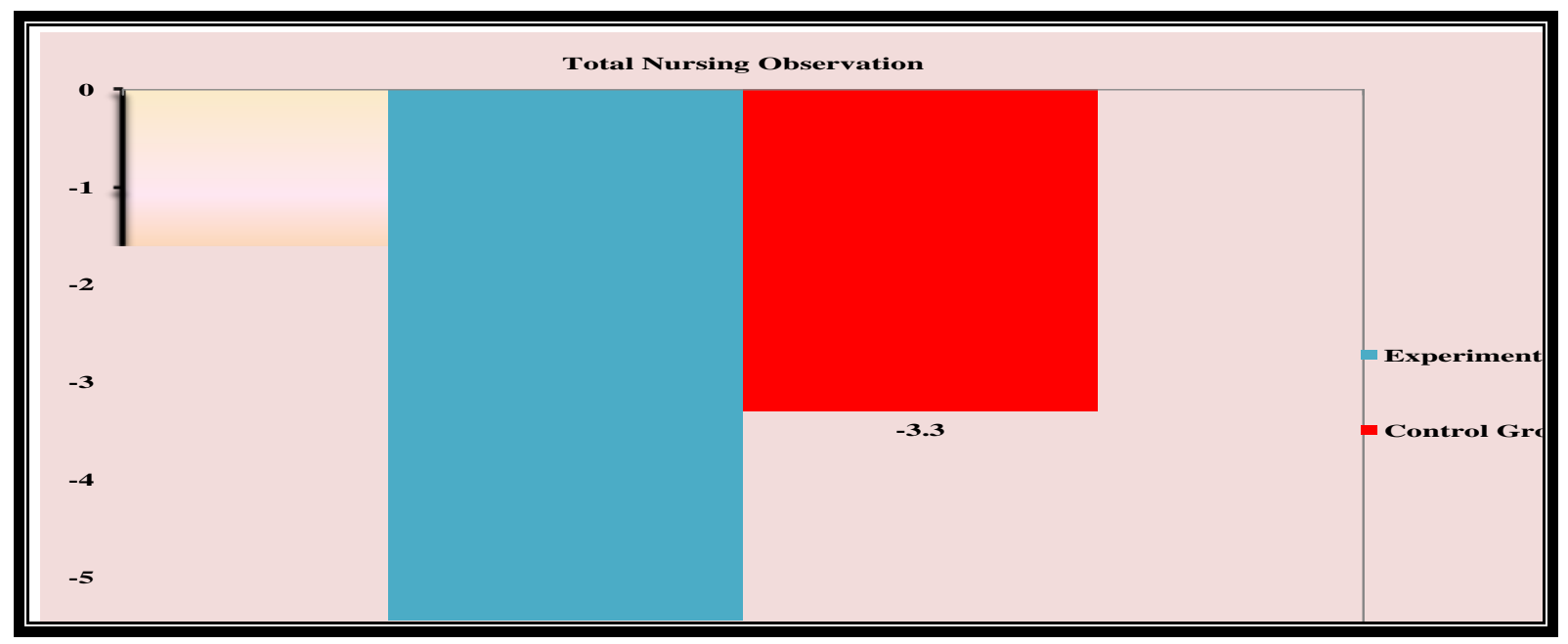

Figure (2) : Mean change of scores of patient's daily living activity measured by Nursing Observation Rating Scale of schizophrenic patient after implementation of physical program in experimental group versus control group.

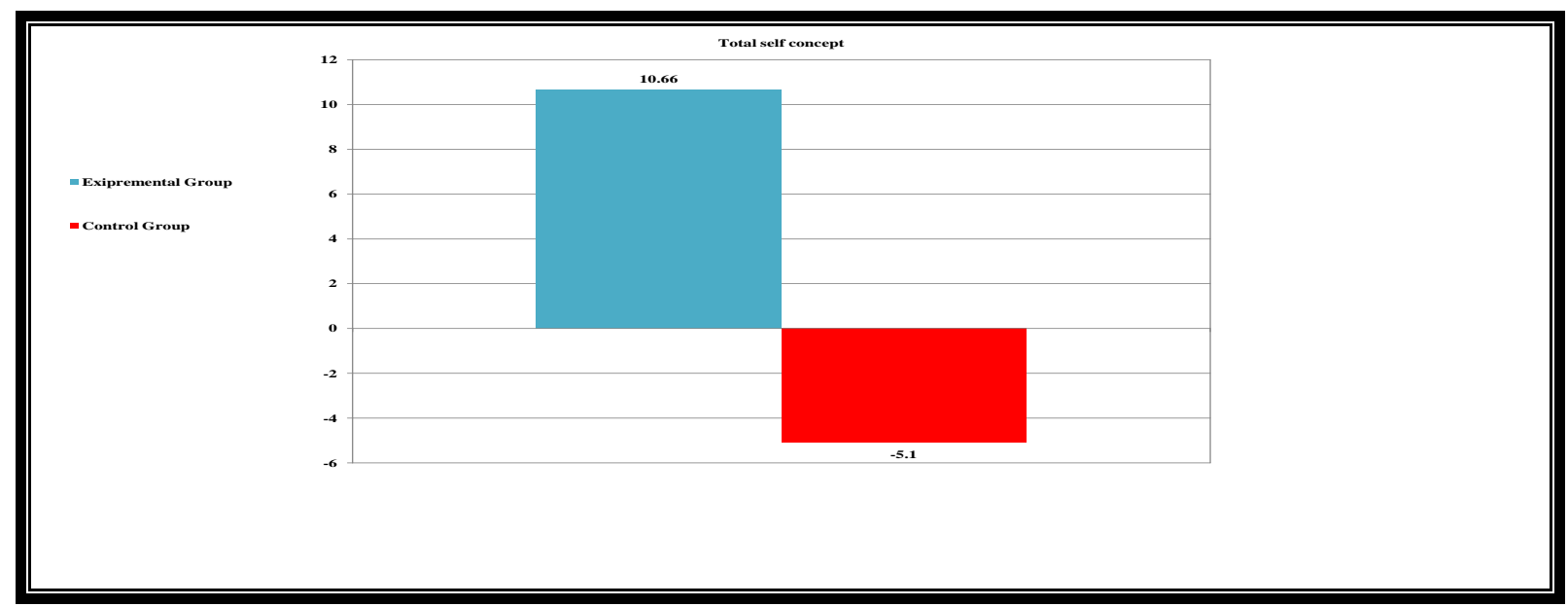

Figure (3) : Mean change of scores of self concepts scales of experimental group after implementation of physical program versus control group. 
Table (2): Significance of differences between patients in the pre implementation and post implementation phase as regard PANSS (No. 50 each)

\begin{tabular}{|c|c|c|c|c|c|c|c|c|}
\hline \multirow[t]{2}{*}{ Variables } & \multicolumn{2}{|c|}{$\begin{array}{c}\text { Pre } \\
\text { Implementation } \\
\text { of program for } \\
\text { experimental } \\
\text { \&control group }\end{array}$} & \multicolumn{2}{|c|}{$\begin{array}{l}\text { Immediate post } \\
\text { Implementation } \\
\text { of program for } \\
\text { experimental } \\
\text { \&control group }\end{array}$} & \multicolumn{2}{|c|}{$\begin{array}{c}\text { Experimental } \\
\text { Pre Vs post }\end{array}$} & \multicolumn{2}{|c|}{$\begin{array}{c}\text { Control } \\
\text { Pre Vs post }\end{array}$} \\
\hline & $\chi^{2}$ & P. value & $\chi^{2}$ & P. value & t- test & P. value & t- test & P. value \\
\hline Total Positive subscale & 4.499 & $0.034^{*}$ & 0.004 & 0.948 & 8.02 & $0.000 * *$ & 4.219 & $0.000 * *$ \\
\hline Total Negative subscale & 4.354 & $0.037^{*}$ & 0.230 & 0.631 & 7.2 & $0.000 * *$ & 3.023 & $0.004 * *$ \\
\hline $\begin{array}{l}\text { Total General } \\
\text { psychopathology } \\
\text { subscale }\end{array}$ & 10.931 & $0.001 * *$ & 1.827 & 0.177 & 10.4 & $0.000 * *$ & 5.954 & $0.000 * *$ \\
\hline Total PANAS Scale & 9.265 & $0.002 * *$ & 0.679 & 0.410 & 10.3 & $0.000 * *$ & 6.756 & $0.000 * *$ \\
\hline
\end{tabular}

*Means there is significant difference $* * P<0.001$, * $P<0.005$

Table (3): Significance of differences among experimental and control group as regard their scores of Nursing Observation Rating Scale (No. 50 each).

\begin{tabular}{|c|c|c|c|c|c|c|c|c|}
\hline \multirow[t]{2}{*}{ Variables } & \multicolumn{2}{|c|}{$\begin{array}{c}\text { Pre } \\
\text { Implementation } \\
\text { of program for } \\
\text { experimental } \\
\text { \&control group }\end{array}$} & \multicolumn{2}{|c|}{$\begin{array}{l}\text { Immediate post } \\
\text { Implementation } \\
\text { of program for } \\
\text { experimental } \\
\text { \&control group }\end{array}$} & \multicolumn{2}{|c|}{$\begin{array}{l}\text { Experimental } \\
\text { Pre \& post }\end{array}$} & \multicolumn{2}{|c|}{$\begin{array}{c}\text { Control } \\
\text { Pre Vs post }\end{array}$} \\
\hline & $\mathrm{X}^{2}$ & P. value & $\mathrm{X}^{2}$ & P. value & T-value & P. value & T-value & P. value \\
\hline 1. personal appearance & 0.118 & 0.732 & 0.473 & .492 & 5.600 & $0.000 *$ & 4.063 & $0.000^{*}$ \\
\hline $\begin{array}{l}\text { 2. Mannerisms \& } \\
\text { Posturing }\end{array}$ & 6.011 & 0.014 & 1.430 & .232 & 3.961 & $0.000 *$ & 1.941 & 0.058 \\
\hline 3. Thought \&talk & 3.795 & 0.051 & 24.020 & $0.000 *$ & 1.944 & 0.058 & 0.711 & 0.481 \\
\hline 4. Mood \& affect & 0.942 & 0.332 & 1.117 & 0.291 & 1.990 & 0.052 & 2.793 & $0.007 *$ \\
\hline 5. Motor activity & 0.378 & 0.539 & 0.667 & 0.414 & 1.441 & 0.156 & 2.694 & 0.010 \\
\hline 6. Irritability & 0.007 & 0.934 & 0.360 & 0.549 & 3.209 & 0.002 & 2.804 & 0.007 \\
\hline $\begin{array}{l}\text { 7. Social competence } \& \\
\text { social performance }\end{array}$ & 1.370 & 0.242 & 0.003 & 0.956 & 2.567 & $0.013^{*}$ & 1.939 & 0.058 \\
\hline 8. Delusion & 0.554 & 0.457 & 0.234 & 0.629 & 0.659 & 0.513 & 0.805 & 0.424 \\
\hline $\begin{array}{l}\text { Total Observation } \\
\text { Rating Scale }\end{array}$ & 1.839 & 0.175 & 0.001 & 0.978 & 3.439 & $0.001 *$ & 2.919 & $0.005^{*}$ \\
\hline
\end{tabular}

* Means there is significant difference

Table (4): Significances of differences among experimental and control group of Self Concepts Scale (No. 50 each).

\begin{tabular}{|c|c|c|c|c|c|c|c|c|}
\hline \multirow[t]{2}{*}{ Variables } & \multicolumn{2}{|c|}{$\begin{array}{c}\text { Pre } \\
\text { Implementation } \\
\text { of program for } \\
\text { experimental } \\
\text { \&control group }\end{array}$} & \multicolumn{2}{|c|}{$\begin{array}{l}\text { Immediate post } \\
\text { Implementation } \\
\text { of program for } \\
\text { experimental } \\
\text { \&control group }\end{array}$} & \multicolumn{2}{|c|}{$\begin{array}{c}\text { Experimental } \\
\text { Pre Vs post }\end{array}$} & \multicolumn{2}{|c|}{$\begin{array}{c}\text { Control } \\
\text { Pre Vs post }\end{array}$} \\
\hline & $\mathbf{X}^{2}$ & P. value & $\mathbf{X}^{2}$ & P. value & t-test & P. value & t-test & P. value \\
\hline Psychological self & 0.627 & 0.428 & 6.587 & $0.010 *$ & -2.47 & $0.017^{*}$ & 2.49 & $0.016^{*}$ \\
\hline Social self & 0.310 & 0.577 & 13.280 & $0.000 *$ & -2.59 & $0.013 *$ & 3.59 & $0.001 *$ \\
\hline Sexual self & 9.314 & $0.002 *$ & 0.015 & 0.902 & 4.24 & $0.000 *$ & 1.07 & 0.290 \\
\hline Family self & 7.867 & $0.005^{*}$ & 19.764 & $.000 *$ & -1.64 & 0.107 & 3.17 & $0.003 *$ \\
\hline Coping self & 1.125 & 0.289 & 11.717 & $.001 *$ & -3.78 & $0.000 *$ & 2.43 & $0.019 *$ \\
\hline Total self concept & 0.452 & 0.501 & 16.739 & $.000 *$ & -3.44 & $0.001 *$ & 4.67 & $0.000 *$ \\
\hline
\end{tabular}

* Means there is significant difference 
Table (1) : The study included 100 patients divided into two groups experimental group includes fifty patients and control group includes fifty patients. The mean age of the experimental group was $33.4 \pm 11.6$ years ranged from 20-40 years old, while age was $30.96 \pm 10.04$ years ranged from 20-40 years old for control group. As regard marital status; $60 \%$ of experimental group were single, $34 \%$ were married, and $6 \%$ were divorced. While $70 \%$ were single, $22 \%$ were married and $6 \%$ only were divorced on control group. Regarding occupation it was clear that $48 \%$ of experimental group do not work, $44 \%$ were workers, while $50 \%$ have work, $44 \%$, were not working and $6 \%$ were employees in control group.

As regard level of education the table No (1) showed that, $60 \%$ of experimental group have secondary school, $34 \%$ were illiterates, and $4 \%$ have university education and $62 \%$ were student, $30 \%$ were illiterate, $4 \%$ have secondary level of education, and $4 \%$ have university education in control group. The majority of experimental and control group (80\% \& 82\%) respectively lies at the middle socioeconomic class.

Fig. (1) : Shows mean change of scores at different subscale of PANSS. It showed that after implementation of physical program, it clear that there are significant improvements of mean scores of PANSS as regard total positive, negative, general subscales and total PANSS score in experimental more than control group.

Fig. (2) : Mean change of scores of patient's daily living activity measured by Nursing Observation Rating Scale of schizophrenic patient after implementation of physical program in experimental group versus control group. It showed significant differences of mean scores of NORS as regard total nursing observation in experimental than in control group.

Fig. (3) : Mean change of scores of self concepts scales of experimental group after implementation of physical program versus control group. It showed that statistical significant differences of scores of total self concept in experimental group than in the control group, which showed decrease in their score at total self concept.

Table (2) : The experimental group have significant higher mean scores than control group as regard total positive subscale $(\mathrm{p}=0.03)$, total negative subscale $(\mathrm{p}=0.03)$, total general psychopathology subscale $(\mathrm{p}=0.001)$ and total PANSS scores $(\mathrm{p}=0.002)$. After the implementation of physical program: there are no significant differences among the experimental group and controls as regard total positive subscale $(\mathrm{p}=.948)$, total negative subscale $(\mathrm{p}=.631)$, total general psychopathology subscale $(\mathrm{p}=.177)$ and total PANSS scores $(p=.410)$. Comparing scores of the patients at the end point by their scores at the starting point: There are significant differences among the experimental group in the post implementation phase of physical exercises program than their scores at the starting point as regard total positive subscale, total negative subscale, total general psychopathology subscale and total PANSS scores $(p=0.000)$. The same is also true for the control group.

Table (3) : The experimental group have significant higher mean scores than control group as regard total NORS $(\mathrm{p}=.001)$. After the implementation of physical program: there are no significant differences among the experimental group and controls as regard total NORS $(\mathrm{p}=.978)$. Comparing scores of the patients at the end point by their scores at the starting point: There are significant differences among the experimental group in the post implementation phase of physical exercises program than their scores at the starting point as regard their scores of total observation rating scales $(\mathrm{p}=.001)$, personal appearance $\quad(\mathrm{p}=.000), \quad$ mannerisms\& posturing $(\mathrm{p}=.000)$, and irritability $(\mathrm{p}=.000)$. The same is true among the control group except that of thought and talk were insignificant while motor activity is significant (0.01).

Table (4) : The experimental group have significant higher mean scores than control group as regard total self concept $(p=.000)$. After the implementation of physical program: there are significant differences among the experimental group and controls as regard total self concept $(\mathrm{p}=.001)$. Comparing scores of the patients at the end point by their scores at the starting point: There are significant differences among the experimental group in the post implementation phase of physical exercises program than their scores at the starting point as regard their scores of total self concept $(\mathrm{p}=.000)$, social self $(\mathrm{p}=.000)$, family self $(\mathrm{p}=.000)$, and coping self $(\mathrm{p}=.001)$. The same is true among the control group except that of sexual self and family self were significant $(P=0.02,0.005)$ respectively.

\section{Discussion}

Schizophrenia is a major type of psychotic disorders which affect individuals at age 15 and 25years. Men tend to develop schizophrenia slightly earlier than women after age of thirty, influence their marital status Rössler et al., (1992), occupations, health and quality of life Bejerholm \& Eklund, (2007).

Patients in the present study have onset of illness at age ranged from 20-40 years old with mean age 33.4 \pm 11.6 years, which is same for the control group (2040 years old with mean age $30.7 \pm 10.04$ ). As regard patients marital statues $60 \%$ \& $70 \%$ of experimental and control schizophrenics, respectively were single. 
Also $48 \%$ and $50 \%$ of them were non workers. Again, $60 \%$ of the experimental group has secondary school education and $62 \%$ of the control still student It is common to see schizophrenic patients in different research setting with similar demographic characteristics. Bassilios (2005) who studied effect of physical activity on schizophrenic patients describe the participants and non participants as follow; the mean age of the participant was 38.6 \pm 10.2 , non participant was $36.1 \pm 12.5,69.5 \%$ and $63.2 \%$ of the participant and non participant, respectively, never married and $83.7 \%$ of the participants were unemployed. Yıldız et al., (2010) found the mean age was 23.5 years with no difference between females and males and $68 \%$ were never married. Babu, et al., (2012) found that $50 \%$ of experimental group were married which is the same for control group. Pesek et al., (2011) found that $31 \%$ was employed and $41 \%$ was unemployed. They found that $44 \%$ have senior high school education, $22 \%$ was students and $19 \%$ have university education.

According to Vancampfort et al., (2012) who found that lower physical activity participant of schizophrenic patients has been associated with greater negative symptoms and reduced functional exercise capacity has been associated with poorer functional outcome and more severe negative, depressive, and cognitive symptoms. On the other hand Faulkner \& Sparkes (1999) reported that exercise is shown to reduce auditory hallucinations, raise self-esteem, and improve sleep patterns and general behaviour in people living with schizophrenia.

Exercise is one of the most acknowledged interventions on schizophrenic patients exercise/sports have been recognized to have a positive impact on cognition and psychiatric symptoms of schizophrenia Vancampfort, (2012). Recent neuroscience research has presented increasing evidence concerning the neurobiological mechanism involved in the positive effect of exercise on cognition in the general population Hillman, (2008). In addition, a recent study has demonstrated that exercise induced an increase in hippocampal volume and improvement in short-term memory in schizophrenia Pajonk, (2010). In the same context, Leutwyler et al., (2012) added that, for a physical activity intervention to be successful in treatment of schizophrenic spectrum disorders, it must include components to enhance cognition and diminish psychiatric symptoms.

These results are congruent with the present study in which both the experimental and control group showed improvement as regard total PANSS and nursing observation rating scales and self concepts scale scores. However, experimental group showed significant more improvement than the control group as regard total positive subscale, total negative subscale, total general psychopathology sub scale and total PANSS scores. They also, showed significant differences (as reported through nursing observations) as regard their total scores at Nursing Observation Rating Scale in comparison to the control group. These improvement includes different domains of the scale; personal appearance, mannerisms\& posturing, irritability, and social competence \& social performance.

These results are consistent with Gorczynski \& Faulkner (2010) who found that exercise significantly improved negative subscale of Positive and negative syndrome scale [PANSS] and relatively effects positive symptoms. Also, they found that Physical health improved significantly in the exercise group compared with those in standard care.

In addition to these improvement also, reported by Scheewe et al., (2013) they found that exercise therapy, when performed once to twice a week, improves mental health and cardiovascular fitness and reduce need of care in patients with schizophrenia. Contrary to this, Heggelund et al., (2011) in their study of the effect of aerobic intensity training on patient with schizophrenia, the psychiatric symptoms, expressed as the Positive and Negative Syndrome Scale (PANSS) and the Calgary Depression Scale for Schizophrenia (CDSS), did not improve in either those performed high aerobic intensity training treatment or playing computer game group. Study the effect of physical exercise on self concept in the present study, the experimental group showed significant improvement of their mean scores than control group as regard total self concepts . This, Included also, improvement in psychological self, social self, sexual self, and coping self.

This is in agreement with the findings of Taylor et al., (1985) who reported that, physical exercises improve mental health and prevent mental disorders by improving self confidence, self-concept, and cognition. Callaghan, (2004) who in a trial to use exercises as means of preventing disease and promoting health and well beginning. He found evidence that exercise have beneficial effect for mental health: it reduces anxiety, stress, depression, negative mood, and improves self-esteem and cognitive functioning.

Also, García-Martínez et al., (2012) in their study on patients with fibromyalgia found that statistically significant improvements in self-esteem, self-concept scores that correlated positively with role emotional, and mental health. Also, they found no significant 
correlation existed between self-esteem or selfconcept and isometric strength, muscular endurance or flexibility exercises. The impact of activity intervention on self-concept among sedentary adolescent females was studied by Schneider et al., (2008) they found that, the intervention of physical activity had a significant positive impact on participation in vigorous activity and cardiovascular fitness. The intervention did not significantly influence any of the self-concept dimensions overall. However, they found a three-way interaction such as there was an increase in global physical self-concept among those intervention participants who have increased cardiovascular fitness.

\section{Conclusion}

Based on the results of the present study, it can be concluded that, there was improvement in physical health, psychological and self concepts of schizophrenic patients. Also the drug and physical exercises for schizophrenic patients contributes the best patient care and take measure to help treatment them. Nurses will be able to offer better care through the use of physical activity as nursing intervention for Schizophrenics.

\section{Recommendations}

Based on the previous findings of the present study, the following recommendations are suggested

1. Development of management plan for schizophrenic patients including physical activity program to improve out come of their treatment.

2. Increase the awareness of family care givers of schizophrenic patients about the importance of physical exercises for patients through health education and training.

3. Physical exercises to be apart of activities of daily living for schizophrenic patients.

\section{Reference}

1. Abo El Maged M., (2001) : Self concept and quality of life among adolescent girls. Unpublished Master thesis, Assiut University, Faculty of Nursing.

2. American Psychiatric Association, (2000): Diagnostic and Statistical Manual of Mental Disorders Fourth edition Text Revision (DSMIV-TR).available at www.psych.org.

3. Astafiev S., Stanley C., Shulman G., Corbetta M., (2004): Extrastriate body area in human occipital cortex responds to the performance of motor actions. Nat Neurosci 7: 542548. | Article | PubMed
4. Babu Paikkatt, Amool Ranjan Singh, Pawan Kumar Singh, and Masroor Jahan (2012): Efficacy of yoga therapy on subjective wellbeing and basic living skills of patients having chronic schizophrenia, over looked http://www.ncbi.nlm.nih.gov.

5. Bassilios, B., (2005): Physical exercise activity in individuals with schizophrenia. Doctorate, School of Behavioral Science, Department of Psychology, The University of Melbourne, over locked http://dtl.unimelb.edu.au

6. Bejerholm, U., \& Eklund, M., (2007): Occupational engagement in persons with schizophrenia: relationships to self-related variables, psychopathology, and quality of life, out look http://www.ncbi.nlm.nih.gov.

7. Berg, A., \& IR Hallberg (2010): Psychiatric nurses' lived experiences of working with inpatient care on a general team psychiatric ward." Journal of Psychiatric \& Mental Health Nursing $7.4:$ 323-333.

8. Bonini L., \& Ferrari P., (2011): Evolution of mirror systems: a simple mechanism for complex cognitive functions. Ann N Y Acad Sci 1225: 166-175.

9. Buccino G., \& Amore M., (2008) : Mirror neurons and the understanding of behavioural symptoms in psychiatric disorders. Curr Opin Psychiatry 21: 281-285.

10. Callaghan P., (2004): Exercise: a neglected intervention in mental health care?, Journal of Psychiatric and Mental Health Nursing 11, 476483, City University, London, UK

11. Calvo-Merino B., Glaser D., Grezes J., Passingham R., Haggard P., (2005) : Action observation and acquired motor skills: an FMRI study with expert dancers. Cereb Cortex 15: 1243-1249.

12. Cohen, S., \& Williamson, G., (1991): Stress and infectious disease in humans. Psychological Bulletin, 109, 5-24.

13. De Vos N., Singh N., Ross D., Stavrinos T., et al., (2005) : Optimal Load for Increasing Muscle Power During Explosive Resistance Training in Older Adults". The Journals of Gerontology 60A (5): 638-647.

14. Downing P., Jiang Y., Shuman M., \& Kanwisher N., (2001) : A cortical area selective for visual processing of the human body. Science 293: 2470-2473.

15. Faulkner, G., \& Sparkes, A., (1999): Exercise as a therapy for schizophrenia: An ethnographic study. Journal of Sport and Exercise Psychology, 21, 52-69.

16. García-Martínez A., De Paz J., \& Márquez S., (2012) : Effects of an exercise programme on 
self-esteem, self-concept and quality of life in women with fibromyalgia: a randomized controlled trial, out look http://www.ncbi.nlm.nih.gov/pubmed.

17. Gorczynski P., \& Faulkner G., (2010): Exercise therapy for schizophrenia. Cochrane Database Syst Rev.

18. Gorczynski P., \& Faulkner G., (2011): schizophrenia available at www.summaries.cochrane.org

19. Green A., Patel, J., Goisman, R., Allison, D., \& Blackburn, G., (2000): Weight gain from novel antipsychotic drugs: Need for action. General Hospital Psychiatry, 22, 224-235.

20. Heggelund J., Nilsberg G., Hoff J, Morken G., Helgerud J., (2011): Effects of high aerobic intensity training in patients with schizophrenia: a controlled trial, Nord J Psychiatry. Sep;65(4):269-75.

21. Hillman C., Erickson K., \& Kramer A., (2008): Be smart, exercise your heart: exercise effects on brain and cognition. Nat Rev Neurosci 9: 58-65.

22. Honigfeld G., Roderic D., Gillis, C., \&Jamess K., (1966) : NOSIE-30: a treatment-sensitive ward behavior scale. Psychological Reports: Volume 19, Issue , pp. 180-182.

23. Key S., Fiszbein A., \& Opler L., (1987) : Positive \& Negative Syndrome Scale (PANSS) for schizophrenia. Schizophrenia Bulletin; 2:261-276.

24. Lawlor, D., \& Hopker, S., (2008): The effectiveness of exercise as an intervention in the management of depression: systematic review and meta-regression analysis of randomized controlled trials, available at www.bmj.com

25. Leutwyler H., Hubbard E., Jeste D., Miller B., \& Vinogradov S.,(2012): Associations of Schizophrenia Symptoms and Neurocognition With Physical Activity interventions.

26. Meyer, T., \& Broocks, A., (2000) : Therapeutic Impact of Exercise on Psychiatric Diseases: Guidelines for Exercise Testing and Prescription. Spot medicine, Volume 30, Number 4, October, pp. 269-279(11).

27. O'Connor D., Crowe M., \& Spinks W., (2005): "Effects of static stretching on leg capacity during cycling". Turin 46 (1): 52-56.

28. Pajonk F., Wobrock T., Gruber O., Scherk H., Berner D., \& Kaizl I., (2010):Hippocampal plasticity in response to exercise in schizophrenia. Arch Gen Psychiatry 67: 133143.

29. Pesek M., Mihoci J., Medved K., \& Šolinc N., (2011): Long term groups of patients with psychosis: Physical activity and medical treatment Psychiatria Danubina, Vol. 23, Suppl. 1, pp 149-154.

30. Rössler A., Fätkenheuer B., Löffler W., Maurer W., \& Häfner (1992): age of onset in schizophrenia influenced by marital status, Social Psychiatry and Psychiatric Epidemiology , Volume 27, Issue 3, pp 122-128

31. Scheewe T., Backx F., Takken T., Jörg F., van Strater A., Kroes A., Kahn R., \& Cahn W., (2013) : Exercise therapy improves mental and physical health in schizophrenia: a randomised controlled trial, overlooked http://www.ncbi.nlm.nih.gov

32. Schneider M., Dunton F., \& Cooper (2008) : Physical Activity and Physical Self-Concept among Sedentary Adolescent Females; An Intervention Study, available at http://www.ncbi.nlm.nih.gov

33. SPSS Inc., (2009) : PASW Statistics for Windows, Version 18.0. Chicago, available at https://www-01.ibm.com

34. Stathopoulou, G., Powers, M., Berry, A., Smits, A., \& Otto, M., (2006): Exercise Interventions for Mental Health: A Quantitative and Qualitiative Review. Clinical Psycholigical Science and Practice, vol. 13, pp. 179-193.

35. Strohle, A., Feller, C., Onken, M., Godemann, F., Heinz, A., \& Dimeo, F., (2005): The acute antipanic activity of aerobic exercise. American Journal of Psychiatry 162, 2376-2378.

36. Takahashi H., Matsui H., Camerer C., Takano H., Kodaka F., \& Ideno T., (2010): Dopamine D receptors and nonlinear probability weighting in risky choice. J Neurosci 30: 1656716572.

37. Takahashi H., Shibuya T., Kato M., Sassa T., Koeda M., \& Yahata N., (2008): Enhanced activation in the extrastriate body area by goaldirected actions. Psychiatry Clin Neurosci 62: 214-219.

38. Taylor C., Sallis J., \& Needle R., (1985): variables, psychopathology, and quality of life. American Journal of Occupational Therapy, 61, 21-32. available at http://www.ncbi.nlm.nih.gov

39. Vancampfort D., Probst M., Helvik Skjaerven L., Catalan-Matamoros D., LundvikGyllensten A., \& Gomez-Conesa A., (2012): Systematic review of the benefits of physical therapy within a multidisciplinary care approach for people with schizophrenia. Phys Ther 92: 11-23.

40. WHO (2011) : Schizophrenia, available at www.who.int

41. Wilmore, J., \& Knuttgen, H., (2003): Aerobic Exercise and Endurance Improving Fitness for 
Health Benefits. The Physician and Sports medicine, 31(5). 45. Retrieved October 5, 2006, from ProQuest database.

42. Yıldız M., Yazıcı A., \& Böke O., (2010) :

Demographic and clinical characteristics in schizophrenia: a multi center cross-sectional case record study, over looked http://www.ncbi.nlm.nih.gov. 